\title{
Effects of sacral nerve electrical stimulation on 5-HT and 5-HT3AR/5-HT4R levels in the colon and sacral cord of acute spinal cord injury rat models
}

\author{
YI ZHU ${ }^{12^{*}}$, JIE CHENG $^{3^{*}}$, JICHAO YIN $^{4}$, YUJIE YANG $^{5}$, JIABAO GUO $^{6}$, \\ WENYI ZHANG ${ }^{7}$, BING XIE $^{8}$, HAIXIA LU ${ }^{9}$ and DINGJUN HAO ${ }^{1}$
}

\begin{abstract}
${ }^{1}$ Department of Spine Surgery, Honghui Hospital, Xi'an Jiaotong University, Xi'an, Shaanxi 710054;
${ }^{2}$ Center of Musculoskeletal Pain Diagnosis and Treatment, The Fifth Affiliated Hospital of Zhengzhou University, Zhengzhou, Henan 470000; ${ }^{3}$ College of Acupuncture and Tuina, Nanjing University of Chinese Medicine, Nanjing, Jiangsu 210023;

${ }^{4}$ Department of Orthopaedics and Traumatology, Xi'an Hospital of Traditional Chinese Medicine, Xi'an, Shaanxi 710000;

${ }^{5}$ Department of Biomedical Sciences, City University of Hong Kong, Hong Kong, SAR 999077; ${ }^{6}$ Department of Sport Rehabilitation, Shanghai University of Sport, Shanghai 200438; ${ }^{7}$ Rehabilitation Medicine Center, The First Affiliated Hospital of Nanjing Medical University, Nanjing, Jiangsu 210000; ${ }^{8}$ Department of Orthopedics and Traumatology, Jiangyin Orthopedics Hospital of Traditional Chinese Medicine, Jiangyin, Jiangsu 214400; ${ }^{9}$ Institute of Neurobiology, Xi'an Jiaotong University Health Science Center, Xi'an, Shaanxi 710061, P.R. China
\end{abstract}

Received October 31, 2018; Accepted October 31, 2019

DOI: $10.3892 / \mathrm{mmr} .2020 .11148$

\begin{abstract}
Spinal cord injury (SCI) often leads to defecation dysfunction. Sacral nerve electrical stimulation (SNS) therapy could improve defecation function. The present study aimed to assess SNS therapy, with regard to the levels of serotonin (5-HT) and its receptors (5-HT3AR and 5-HT4R) in the colon and sacral cord, a rat model of acute severe SCI was used. This rat model was made using the New York University Impactor device. Model rats were randomized to the SCI and SNS (electrical stimulation on the $\mathrm{S} 3$ nerve) groups. After 14 days of treatment, enteric transmission function was assessed. 5-HT
\end{abstract}

Correspondence to: Dr Haixia Lu, Institute of Neurobiology, Xi'an Jiaotong University Health Science Center, 76 Nanguo Road, Xi'an, Shaanxi 710061, P.R. China

E-mail: hx101@xjtu.edu.cn

Dr Dingjun Hao, Department of Spine Surgery, Honghui Hospital, Xi'an Jiaotong University, 76 Nanguo Road, Beilin, Xi'an, Shaanxi 710054, P.R. China

E-mail: haodingjun@126.com

${ }^{*}$ Contributed equally

Abbreviations: NYU, New York University; SCI, spinal cord injury; CNS, central nervous system; IHC, immunohistochemistry; AOD, average optical density; 5-HT, serotonin; 5-HTR, serotonin receptor

Key words: sacral nerve electrical stimulation, spinal cord injury, defecation reflex, 5-HT, 5-HT3AR, 5-HT4R and 5-HT3AR/5-HT4R were measured by ELISA, quantitative PCR, immunohistochemistry and western blotting. In SCI rats, SNS significantly increased the quantity of feces, shortened the time to the first fecal passage, and improved fecal texture and colon histology. SNS elevated 5-HT contents in the colon and spinal cord, and enhanced 5-HT3AR/5-HT4R protein expression and distribution in the colonic myenteric plexus and mucosa, sacral intermediolateral nucleus and dorsal horn. SNS upregulated the relative expression levels of 5-HT3AR/5-HT4R mRNA and protein in the colon and spinal cord. SNS can improve defecation and accelerate the recovery of colonic transmission functions in rat models of acute SCI. These effects involved upregulation of the 5-HT/5-HT3AR/5-HT4R axes.

\section{Introduction}

Spinal cord injury (SCI) often causes motor, sensorial and autonomic nervous system dysfunction of the affected segment (1). Normal defecation processes are co-governed by the central nervous system (CNS) and the autonomic nervous system [including the enteric nervous system (ENS)] (2). When the spinal cord is impaired, defecation is no longer under the control of the brain (2). Over $1 / 3$ of patients with SCI have defecation dysfunction, which has a serious impact on their quality of life $(3,4)$. When SCI occurs above the conus medullaris, the defecation reflex, which is controlled by the lower defecation center at the sacral cord S2-4, is still intact; when SCI occurs below the conus medullaris, both brain control and the defecation reflex are lost $(3,4)$. The primary pathological manifestations of defecation dysfunction due to SCI are decreased colonic motility and prolonged intestinal transmission time, irrespective of trauma location $(5,6)$. 
The ENS governs gastrointestinal (GI) movements using a variety of neurotransmitters. Serotonin (5-HT) is an important neurotransmitter for modulating GI movement, and it is also a signaling molecule for GI mucosa sensation feedback to the nervous center (7). 5-HT augments mucosa secretion and promotes the proliferation of the GI pacemaker cells, known as interstitial cells of Cajal (ICC) (7-10).

The modulation of GI functions by 5-HT is exerted directly on the smooth muscle, promoting its contraction (7). 5-HT3 receptor (5-HT3R) and 5-HT4R are important 5-HT excitatory receptors and are widely present in the GI tract $(11,12)$. 5 -HT3R is an ion channel linked receptor that promotes GI movement by transmitting fast excitatory postsynaptic potentials at the serotonergic neurons (13). It does this by augmenting the secretion and release of neurotransmitters (including acetylcholine, substance $\mathrm{P}$ and dopamine) (14), and by modulating ICC activities via the regulation of extracellular $\mathrm{Ca}^{2+}$ concentration (15). Additionally, 5-HT3R also mediates the transmission of enteric sensory information to the CNS, thus triggering the GI reflex $(13,15-17)$. The major enteric depot of 5-HT is found in mucosal enterochromaffin cells, which are sensory transducers that use 5-HT to activate both the intrinsic (via 5-HT1PR and 5-HT4R) and extrinsic (via 5-HT3R) primary afferent nerves (18). Moreover, 5-HT3R enhances 5-HT secretion from the gut mucosa (17,19). Five subtypes of 5-HT3R have been characterized, among which 5 -HT3AR is a functional receptor with specific subtype features $(16,20)$. 5-HT4R is a G protein-coupled receptor. At the myenteric plexus, 5-HT4R promotes neurotransmitter release from the cholinergic system, thus improving GI smooth muscle contraction. At the mucosal epithelium, 5-HT4R mediates the transmission of sensory information and augments secretion (21-23). Moreover, 5-HT4R can enhance the pacing of ICCs (24). 5-HT3AR and 5-HT4R are mainly expressed in the myenteric plexus, mucous membrane, submucosal nerves and, in small quantities, in the muscularis (25). Moreover, they are expressed at varying degrees in neurons, epithelial cells, goblet cells, chromaffin cells, Cajal mesenchymal cells and smooth muscle cells (26-28). 5-HT3R and 5-HT4R antagonists decrease GI motility, whereas 5-HT3R and 5-HT4R agonists enhance GI emptying (29-31). 5-HT, 5-HT3AR and 5-HT4R are also present in the spinal cord (32-34). Intestinal serotonergic neurons are mainly distributed in the submucosal plexus and myenteric plexus $(11,12)$. Serotonergic neurons are also distributed in the dorsal horn of the spinal cord, which is related to visceral sensations (32). In addition, there are 5-HT immunopositive nerve fibers in the lateral horn of the spinal cord, which is related to visceral movement $(24,27)$. Synchronous anomalies of 5-HT expression in the spinal cord and colon are detected in some enteric motility disorders (35). Nevertheless, the changes in 5-HT, 5-HT3AR and 5-HT4R in the colon and spinal cord of rats with SCI remain to be clarified.

Sacral nerve electrical stimulation (SNS) enhances the defecation reflex by improving colonic motility and shortening colon transit time, thus alleviating constipation. Therefore, SNS could be a therapeutic option for defecation dysfunction caused by diverse etiologies, including SCI (36-39). Electrical stimulation on nerve $\mathrm{S} 3$ triggers an anterograde impulse on the whole colon that accelerates defecation frequency and quantity $(40,41)$. A previous study suggested that the mechanism of action of SNS on intestinal dysfunction is through the modulation of spinal and/or supraspinal afferent inputs (42). Another study highlighted that the mechanisms of SNS are multifactorial and complex, and involve rectal sensory threshold, recto-anal inhibitory reflex, rectal evacuation and anorectal autonomic function (43). Nonetheless, the neuromodulation mechanism underlying SNS therapy for SCI remains to be determined.

Based on the available data, it was hypothesized that SNS can improve defecation function by increasing 5-HT, 5-HT3AR and 5-HT4R in the colon of rat models of SCI. Therefore, this study aimed to establish a rat model of acute severe SCI (thoracic segments) to assess the influence of SNS on 5-HT, 5-HT3AR and 5-HT4R in the colon and sacral cord, and to explore the potential mechanisms for SNS in promoting defecation reflex.

\section{Materials and methods}

Animals and grouping. A total of 70 healthy adult female Sprague-Dawley rats (specific pathogen-free grade; age, 8 weeks; weight, $200 \pm 20$ g) were purchased from Shanghai SIPPR-Bk Lab Animal Co., Ltd. (license no. SCXK: 2008-0016). The animals were housed at $23 \pm 2^{\circ} \mathrm{C}$, with $12-\mathrm{h}$ light-dark cycles and $50 \%$ humidity. The animals had free access to food and drink, and were adaptively housed for 1 week prior to experiments. The animals were caged individually after surgery. The experiments were approved by the Animal Care and Use Committee of Xi'an Jiaotong University Health Science Center. All efforts were made to minimize animal numbers and suffering.

A total of 20 rats, using a random number table, were randomly assigned to the sham operation group, and the remaining 50 rats underwent severe SCI modeling. During the operation, four rats died, which was within the acceptable limits of the ethical approval obtained for the present study, and two rats were excluded due to modeling failure. Forty rats were randomly selected among the ones with successful modeling, and randomized to the SCI and SNS groups (20 rats/group). The remaining four rats received the same nursing interventions (such as anti-infection treatment and assisted urination) as the rats with SCI. After the experiment was completed, the rats were sacrificed humanly.

The first day of the experiment was modeling. SNS intervention was performed for 14 days, from day 2 to day 15 . On day 16 , the time to first black stools was recorded (fasting started on day 15 and the animals had free access to water for $24 \mathrm{~h}$ ). Dry weight of the fecal pellets was recorded. The animals were sacrificed on day 17 .

Rat model of severe SCI. Prior to the induction of the severe SCI model, the rats were deeply anesthetized by the intraperitoneal injection of $10 \%$ chloral hydrate $(300 \mathrm{mg} / \mathrm{kg})$. Thermal support was provided and the depth of anesthesia was monitored by the toe pinch method. The skin region was disinfected with iodophor and a median incision was made from T10 to T13. The spinous process and vertebral plates were exposed after the dissection of the superficial fascia and the removal of the T11-T12 vertebral plates. A bone window was generated 
and the spinal cord was exposed. SCI was induced by striking the exposed spinal cord using a $10 \mathrm{~g}$ weight falling from $60 \mathrm{~mm}$ with the New York University (NYU) Impactor device (W.M. Keck Center for Collaborative Neuroscience Rutgers, State University of New Jersey); this apparatus was used because it avoids the occurrence of heavy bleeding $(44,45)$. Successful SCI modeling was determined according to the improved Basso, Beattie, Bresnahan locomotor rating (BBB) score (45). In the sham operation group, the spinal cord was exposed at T10-T13, but the NYU impactor was not used. In all rats, the wound was sutured within 5 min and covered with gentamicin ointment.

$B B B$ score. The improved $\mathrm{BBB}$ score was determined to evaluate hind limb motor function (45). The rats were placed in an open space before modeling (day 1), $24 \mathrm{~h}$ after modeling (day 2) and on day 16. The following parameters were observed independently by two observers: Joint motions of the hip, knee and ankle; hind limb weight-bearing condition; walking capability and hind limb-forelimb coordination; trunk stability; paw position; and tail movement. The scores were between 0 and 21 points, higher scores indicated increased improvement of the hind limb motor function.

Post-operative nursing. From the day of modeling, all rats received intraperitoneal injections of gentamicin for 16 days at $5,000 \mathrm{U} / \mathrm{kg}$ once daily. The lower abdomen, perineum and hind limbs of the rats were cleaned daily, and passive movements of the hind limbs were performed daily. The Crede maneuver (46) was applied every $12 \mathrm{~h}$ to assist voiding: The SCI rats were held upright and gentle pressure was applied on the bulging bladder from top to bottom for assisting urination. Before voiding, the bladder was palpated and urinary retention was estimated based on the degree of bladder filling.

The passive movements were performed after Crede-assisted urination. The operator fixed the rat in the prone position with one hand and grasped the toes of one hind limb with the other hand. Then, the rat was pulled rearward and outwardly at a $45^{\circ}$ angle with the spine, until the knee and ankle joints were in complete extension. After this, the hind limb was pushed towards the trunk in the opposite direction until the hip and knee joints were completely flexed and the ankle was completely dorsally flexed. Flexions were performed $60 \mathrm{times} / \mathrm{min}$ for $1 \mathrm{~min}$. The same procedure was performed for the other hind limb. Passive movement of both hind limbs was performed once every $12 \mathrm{~h}$. An observer blinded to grouping observed fur appearance, autonomic activity, food and water intake, defecation and urination and bodyweight during the study.

SNS. At $24 \mathrm{~h}$ after successful modeling, the rats in the SNS group were immobilized in the prone position. Needle electrodes were placed on bilateral S3 neural foramen. The electrodes were connected to a Myolito electrical stimulator (MTR+ Vertriebs GmbH). The stimulation settings were: Pulse width of $0.2 \mathrm{msec}$; frequency of $10 \mathrm{~Hz}$; stimulation duration of $10 \mathrm{sec}$; intervals of $5 \mathrm{sec}$; and current of 2-3 mA. The appropriate stimulation degree was indicated by slight shivering of the tail, but without braying. Each session of SNS lasted $15 \mathrm{~min}$, with one session per day for 14 days.
Assessment of intestinal transmission function. The first black feces were discharged at 8:00 a.m. on the 15th day of the experiment. Then, 10 rats from each group were randomly selected and fasted for $24 \mathrm{~h}$, but with free access to water. At 8:00 a.m. on the 16th day of the experiment, these rats were given $2 \mathrm{ml}$ of $100 \mathrm{~g} / \mathrm{l}$ activated charcoal suspension by gavage. The time interval between charcoal gavage and the first black feces was recorded.

The dry weight of feces discharged within $24 \mathrm{~h}$ was recorded. In the remaining 10 rats/group, on the 16th day of experiment, feces discharged within $24 \mathrm{~h}$ (8:00 a.m.-8:00 a.m.) were collected, dried and weighed.

Tissue sampling. On the 17th day of the experiment, the rats were sacrificed by decapitation after intraperitoneal injection of $10 \%$ chloral hydrate $(400 \mathrm{mg} / \mathrm{kg})$, followed by exposure of the spinal cord at S2-4 (in accordance with the vertebral bodies L3-5). The fresh spinal cord tissue of these segments was rapidly harvested and split into two parts. The abdomen was cut open for the quick dissection of $\sim 1 \mathrm{~cm}$ of distal colon, which was cut open along the longitudinal axis to rinse off colonic contents with physiological saline, and split into two parts. One part of fresh spinal and colon tissues were directly preserved in liquid nitrogen for ELISA, reverse transcription-quantitative PCR (RT-qPCR) and western blotting. The other parts of spinal cord and spread colon tissues were fixed in $4 \%$ paraformaldehyde for hematoxylin-eosin (H\&E) staining and immunohistochemistry (IHC).

Hence, the samples of the colon and spinal tissues (20 rats/group) were both divided into two parts. One part was fixed with $4 \%$ paraformaldehyde, while the other part was stored in liquid nitrogen. Among the 20 samples fixed with 4\% paraformaldehyde, five were randomly selected for H\&E staining, five were randomly selected for IHC and the other 10 were stored for eventual future use. Among the 20 samples stored in liquid nitrogen, 10 were used for ELISA, five were used for RT-qPCR, four were used for western blotting, and the remaining one was stored for eventual future use.

$H \& E$ staining. Colon tissues of 5 rats in each group were fixed in $4 \%$ paraformaldehyde for $24 \mathrm{~h}$ at room temperature $\left(23 \pm 2^{\circ} \mathrm{C}\right)$, followed by routine paraffin embedding, and sectioning at $4 \mu \mathrm{m}$. Tissue slides were subjected to routine H\&E staining, as follows. Dewaxing was performed using xylene and a descending ethanol series $(100,100,95,95,85$ and $75 \%$ ) for $5 \mathrm{~min}$ at each step. The sections were treated with hematoxylin for $5 \mathrm{~min}, 1 \%$ hydrochloric acid in ethanol for $2 \mathrm{sec}$, tap water for $10 \mathrm{~min}$, and eosin for $3 \mathrm{~min}$. The sections were dehydrated in an ascending alcohol gradient $(75,85,95$, 95, 100 and 100\%) and xylene, 3 min each step. The sections were sealed with neutral gum. All steps were performed at room temperature $\left(23 \pm 2^{\circ} \mathrm{C}\right)$. Pathological changes of colon tissues were observed in six different fields and photographed using a DMLS32 optical light microscope (magnification x200; Leica Microsystems GmbH).

ELISA. Colon and spinal cord tissues of 10 rats in each group were homogenized in PBS (weight:volume ratio of 1:9) and supernatants were extracted by centrifugation at $5,000 \mathrm{x} \mathrm{g}$ for $5-10 \mathrm{~min}$ at room temperature $\left(23 \pm 2^{\circ} \mathrm{C}\right)$. The standards 
$(24,12,6,3,1.5$ and $0.75 \mathrm{ng} / \mathrm{ml})$ from the 5-HT ELISA kit (cat. no. 201710; Nanjing Jiancheng Bioengineering Institute Co., Ltd.) and test samples $(50 \mu \mathrm{l})$ were added into the wells. Subsequently, the samples were incubated with horseradish peroxidase-labeled 5-HT antibody $(100 \mu \mathrm{l})$ for $60 \mathrm{~min}$ at $37^{\circ} \mathrm{C}$, as per the kit instructions. Optical density values were measured at a wavelength of $450 \mathrm{~nm}$.

IHC for 5-HT3AR and 5-HT4R. Colon and spinal cord tissues from five rats in each group were fixed in $4 \%$ paraformaldehyde for $>24 \mathrm{~h}$ at room temperature $\left(23 \pm 2^{\circ} \mathrm{C}\right)$, followed by routine paraffin embedding and sectioning $(5-\mu \mathrm{m}$ thick sections). One slide with an intact tissue section from each animal was selected for IHC. For dewaxing and hydration, the sections were successively immersed in xylene, xylene, anhydrous ethanol, 95\% ethanol, 85\% ethanol and 70\% ethanol for 5 min each, followed by rinsing with PBS three times for $3 \mathrm{~min}$ each. Endogenous peroxidase activity was blocked using $3 \% \mathrm{H}_{2} \mathrm{O}_{2}$ for $10 \mathrm{~min}$ at room temperature, followed by rinsing with PBS three times for 3 min each. The sections were blocked with 5\% goat serum (50-100 $\mu$; cat. no. C0265, Beyotime Institute of Biotechnology) for $20 \mathrm{~min}$ at room temperature $\left(23 \pm 2^{\circ} \mathrm{C}\right)$. The primary antibodies (all purchased from Abcam) included anti-5-HT3AR (cat. no. ab13897; 1:100) and anti-5-HT4R (cat. no. ab60359; 1:200). The sections were incubated with the primary antibody solution (50-100 $\mu \mathrm{l})$ overnight at $4^{\circ} \mathrm{C}$, followed by washing three times with PBS, 3 min each. The sections were incubated with horseradish-peroxidase goat anti-rabbit IgG (H+L) secondary antibody (cat. no. 111-035-003; 1:200; Jackson ImmunoResearch Laboratories, Inc.) at $37^{\circ} \mathrm{C}$ for $1 \mathrm{~h}$. Chromogen detection was performed by incubating the sections with DAB solution for $15 \mathrm{~min}$ at room temperature $\left(23 \pm 2^{\circ} \mathrm{C}\right)$. The sections were counterstained with hematoxylin for $10 \mathrm{~min}$ at room temperature $\left(23 \pm 2^{\circ} \mathrm{C}\right)$ and washed with distilled water. Subsequently, the sections were immersed in 70, 85, 95 and $100 \%$ ethanol for $5 \mathrm{~min}$ each, and twice in xylene for $10 \mathrm{~min}$ each. Neutral gum was added to seal the slides. The sections were examined under a DMLS32 optical light microscope (Leica Microsystems GmbH). The positive staining was examined (magnification, $\mathrm{x} 40$, followed by magnifications, x100/x400). Six high-power fields (HPF; magnification, $x 400$ ) were randomly selected on every slide. The JD801 image analysis system (Nanjing Jiancheng Bioengineering Institute Co., Ltd.) was used to measure the average optical density (AOD) of the positive stained area. Image-Pro software (version 6.0.0.309; Media Cybernetics, Inc.) was used to count immunopositive cells in six HPFs (magnification, $\mathrm{x} 400 ; 0.1323 \mathrm{~mm}^{2}$ ) per animal.

$R T$ - $q P C R$. Cryopreserved colon and spinal cord tissues from 5 rats in each group were used for RNA extraction with TRIpure reagent (cat. no. 2702026AX; Beijing Aidlab Biotechnologies Co., Ltd.). Total RNA (2 $\mu \mathrm{g})$ was reverse transcribed to cDNA using a OneScript cDNA Synthesis kit (cat. no. G234; Applied Biological Materials, Inc.), according to the manufacturer's instructions. qPCR was performed using the EvaGreen Express 2X qPCR MasterMix-ROX kit (cat. no. MasterMix-ER; Applied Biological Materials). Fluorescence qPCR was carried out in a TL988-IV qPCR

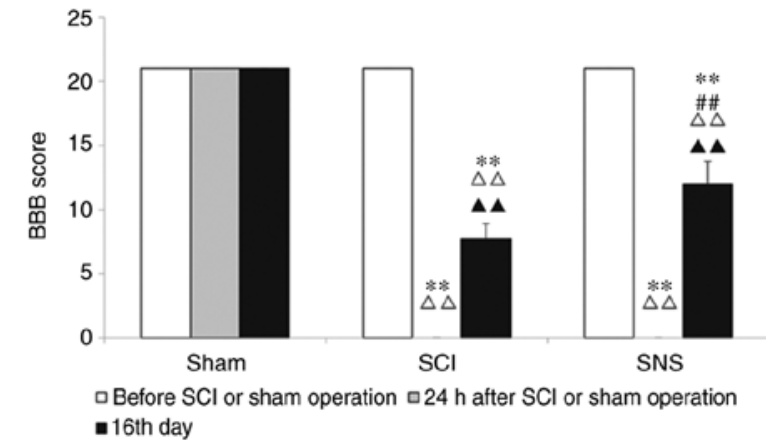

Figure 1. Effects of SNS on the BBB score in rats with SCI, measured before modeling, $24 \mathrm{~h}$ after modeling and on day $16(\mathrm{n}=20) .{ }^{* *} \mathrm{P}<0.01 \mathrm{vs}$. sham; ${ }^{\# \#} \mathrm{P}<0.01$ vs. SCI at the same time point; ${ }^{\Delta \Delta} \mathrm{P}<0.01$ vs. before SCI within the same treatment group; ${ }^{\wedge \Delta} \mathrm{P}<0.01$ vs. $24 \mathrm{~h}$ after SCI within the same treatment group. BBB, Basso, Beattie, Bresnahan locomotor rating; SCI, spinal cord injury; SNS, sacral nerve electrical stimulation.

system (Tianlong Science and Technology Co., Ltd.), in triplicate. The primer pairs used were as follows: 5-HT3AR forward, 5'-GGCACCTGGTCCTAGACAGAA-3' and reverse, 5'-GGTTTCCCATGGCTGAGCAGT-3'; 5-HT4R forward, 5'-CCGTTTCTCCTCATGGTGCT-3' and reverse, 5'-AAC ATCTGGATCTGCTGGGC-3'; and $\beta$-actin forward, 5'-TGG GTATGGAATCCTGTGGCA-3' and reverse, 5'-TGTTGG CATAGAGGTCTTTACGG-3'. The reaction conditions were: Initial denaturation at $95^{\circ} \mathrm{C}$ for $10 \mathrm{~min}$; and 40 cycles of amplification at $95^{\circ} \mathrm{C}$ for $5 \mathrm{sec}$ and $60^{\circ} \mathrm{C}$ for $10 \mathrm{sec}$. The issolution curves of the PCR products were analyzed. The $\mathrm{Cq}$ values were determined using the MED-TL software (version IV; Xi'an Tianlong Science and Technology Co., Ltd.). The relative mRNA expression levels were calculated using the $2^{-\Delta \Delta C q}$ method (47) and normalized to the internal reference gene $\beta$-actin.

Western blotting. Cryopreserved colon and spinal cord tissues were used for western blotting. Proteins were purified with the Protein Extraction kit (cat. no. KGP250; Nanjing KeyGen Biotech Co., Ltd.). Total protein was quantified using a bicinchoninic acid assay and $170 \mu \mathrm{g}$ protein/lane were separated via SDS-PAGE on $10 \%$ gels. The high mass of protein loaded per lane was due to the low expression levels of 5-HT3AR and 5-HT4R in the samples. The separated proteins were subsequently transferred onto nitrocellulose membranes and blocked for 1.5-2 $\mathrm{h}$ at room temperature with 5\% skim milk powder. The membranes were incubated overnight on a shaking plate at $4^{\circ} \mathrm{C}$ with primary antibodies against: 5-HT3AR (1:500; cat. no. ab13897, Abcam), 5-HT4R (1:1,000; cat. no. ab60359; Abcam) and GAPDH (cat. no. E12-052; Nanjing EnoGene Biotech Co., Ltd.). After rinsing with TBST, the membranes were incubated for $1-2 \mathrm{~h}$ at room temperature with a goat anti-rabbit IgG-HRP secondary antibody (1:5,000; cat. no. E1WP318; Nanjing EnoGene Biotech Co.,Ltd.). Protein bands were visualized using the ECL Chemiluminescence kit (cat. no. E1WP3132; Nanjing EnoGene Biotech Co., Ltd.), prior to scanning in the BOX chemiXR5 chemiluminescence imaging system (SynGene Europe). The band densities of the target proteins (5-HT3AR/5-HT4R) were measured using Gel-Pro Analyzer software (version 32; Meyer Instruments) 
A

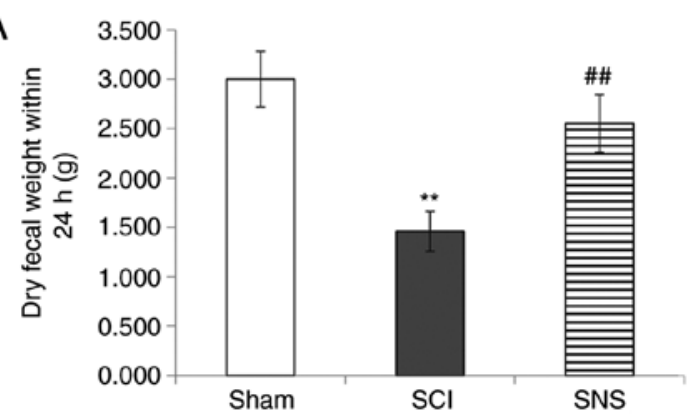

B

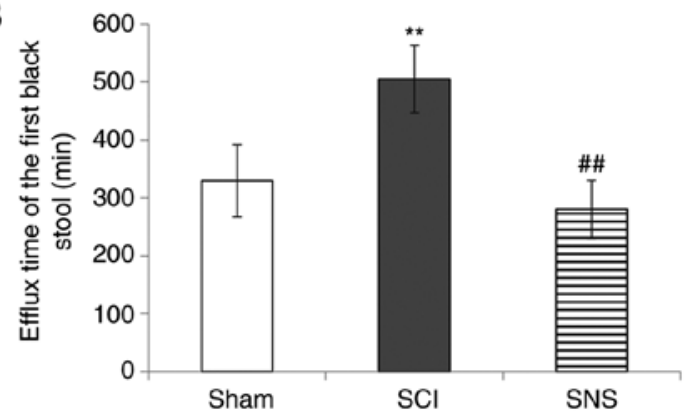

Figure 2. Effects of SNS on intestinal transmission function in rats with SCI. (A) Dry fecal weight within a 24-h light/dark cycle and (B) efflux time of the first black stool were measured on day $16(\mathrm{n}=10) .{ }^{* *} \mathrm{P}<0.01$ vs. sham; ${ }^{\# \#} \mathrm{P}<0.01$ vs. SCI. SCI, spinal cord injury; SNS, sacral nerve electrical stimulation.

with GAPDH as the loading control. The ratio of target protein vs. internal control was considered as the relative expression level of the target proteins.

Statistical analysis. SPSS 16.0 (SPSS, Inc.) was used for statistical analysis. Data were expressed as the mean \pm SD. Analyses of normal distribution and homogeneity of variance were first conducted. For data with normal distribution, comparisons among multiple groups were carried out with one-way ANOVA, as appropriate, with the least significant difference post hoc test (for data with homogeneity of variance) or the post hoc Dunnett's T3 test (for data with heterogeneity of variance). For the BBB score, the Wilcoxon non-parametric test with Bonferroni's correction was used (same experimental group, different time points). For comparisons between unmatched data (same time point, different experimental group), the Mann-Whitney U-test with Bonferroni's correction was used to analyze the data. $\mathrm{P}<0.05$ was considered to indicate a statistically significant difference.

\section{Results}

Severe SCI model establishment. The NYU impactor device was used to establish the rat model of severe thoracic SCI (44). In the sham group, hind limb movement was not affected by the operation, whereas in the SCI and SNS groups, hind limbs presented flaccid paralysis and complete loss of motor function at the early stage after modeling. Within 2 weeks after SCI modeling, the hip and ankle joints of hind limbs presented extensive motion in the SCI and SNS groups (data not shown).

On the 17th day of the experiment, the rats in the sham group showed bright fur, autonomic activity, food and water intake, defecation and urination, and stable body weight (even with some gain). In the SCI group, the rats showed fatigue, irritation and aggressiveness, loose and dim fur, emaciation, decreased autonomic activity, decreased food intake, decreased defecation, urinary retention, hematuria and urinary incontinence (in some rats), as well as muscular atrophy of various degrees in the hind limbs. In the SNS group, the rats showed an improved state and fur condition compared with the SCI group. They showed emaciation, decreased autonomic activity, decreased food intake, decreased defecation (although improved compared with the SCI group) and urinary retention (although milder than in the SCI group; data not shown as it was not an endpoint in the present study).
Before modeling, the BBB scores were 21 points for all rats. At $24 \mathrm{~h}$ after modeling and compared to the sham group, the BBB scores of the SCI and SNS groups were 0 (both $\mathrm{P}<0.01)$. On the 16th day, compared to the sham operation group, BBB scores of the SCI and SNS groups were decreased significantly (both $\mathrm{P}<0.01$ ). Compared with the SCI group, the BBB score of the SNS group was higher $(\mathrm{P}<0.01$; Fig. 1).

SNS improves intestinal transmission function. The effects of SCI and SNS on intestinal functions were observed by the characterization of the fecal pellets and the passage of black fecal pellets. On the 16th day, rats in the sham group showed unobstructed defecation, with fecal pellets of a long grainy shape, discharged as 2-3 consecutive pellets or a single pellet with soft and humid texture. On the other hand, the rats in the SCI group showed constipation, with fecal pellets showing a small grainy shape, discharged as single pellet with hard and dry texture, and the amount of defecation was significantly less than that of the sham group $(\mathrm{P}<0.01$; Fig. $2 \mathrm{~A})$. In the SNS group, rats showed unobstructed defecation, with fecal pellets being slightly smaller than in the sham group and with long grainy shape, discharged as 2-3 consecutive pellets or single pellet with slightly hard texture, and the amount was larger than in the SCI group $(\mathrm{P}<0.01)$.

In addition, the time interval between the operation and subsequent first defecation was different among the three groups $(\mathrm{P}<0.01)$. Compared with the sham group, the discharge of the first black feces was significantly delayed in the SCI group $(\mathrm{P}<0.01)$. Compared with the SCI group, the time interval was significantly shortened in the SNS group $(\mathrm{P}<0.01$; Fig. 2B).

Taken together, these results suggested that SCI significantly impaired intestinal function. SNS could restore, at least in part, intestinal function in SCI rats.

SNS improves the colon histopathological features after SCI. The rats were sacrificed and colon histopathological examination was carried out to determine the effects of SCI and SNS on colon tissues. As shown in Fig. 3, compared with the sham group, the SCI group showed mucosal erosion, lower number of glands, interstitial edema and prominent atrophy of the muscular layer. The SNS group displayed mild atrophy of the muscular layer and proper glands, mild interstitial edema and with colon histology similar to that of the sham group. These 


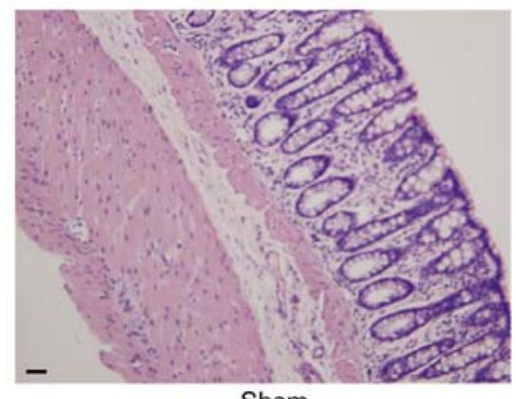

Sham

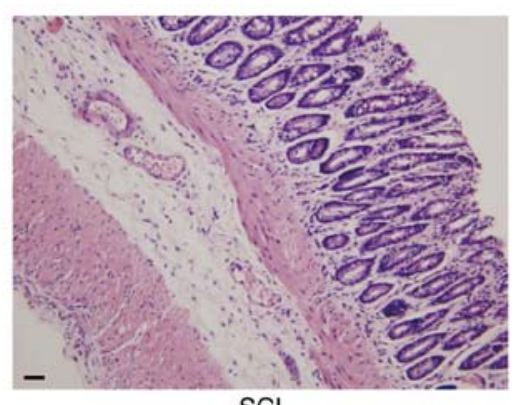

$\mathrm{SCl}$

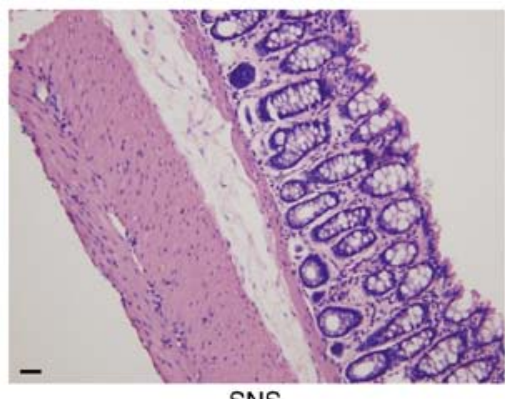

SNS

Figure 3. Pathological changes of colon tissues in the SCI rat model after SNS on the 16th day after modeling. Colon tissues were stained with hematoxylin and eosin and observed under light microscopy (magnification, x200; scale bar, $200 \mu \mathrm{m}$ ). SCI, spinal cord injury; SNS, sacral nerve electrical stimulation.

A

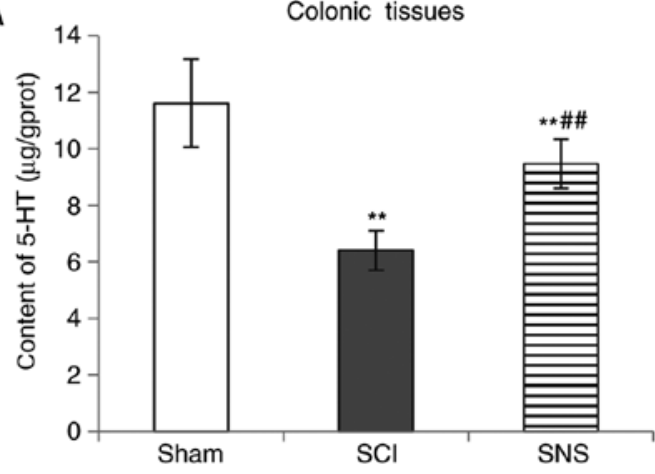

B

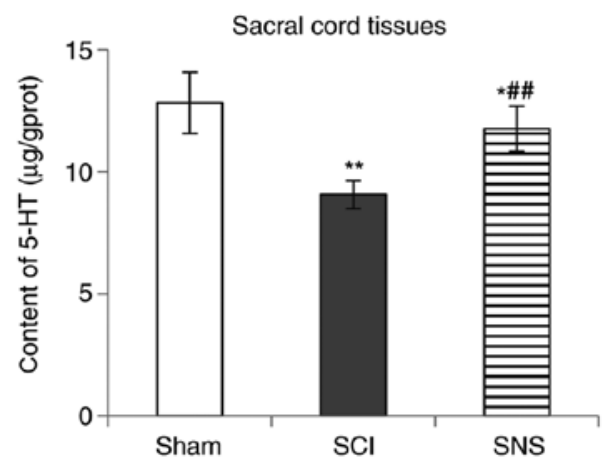

Figure 4. Levels of 5-HT in (A) colon and (B) sacral cord were measured on the 16th day after modeling in rats with SCI and treated with SNS for 14 days $(\mathrm{n}=10) .{ }^{*} \mathrm{P}<0.05$ vs. sham; ${ }^{* *} \mathrm{P}<0.01$ vs. sham; ${ }^{\#} \mathrm{P}<0.01$ vs. SCI. SCI, spinal cord injury; SNS, sacral nerve electrical stimulation; 5-HT, serotonin; Prot, protein.

results suggested that SCI caused marked alterations to colon histology, while SNS could alleviate those changes, at least in part.

SNS increases 5-HT expression in the colon and sacral cord of rats with SCI. The levels of 5-HT in the colon and sacral cord were measured in rats with SCI, and those treated with SNS. As shown in Fig. 4, compared with the sham group, 5-HT expression levels in the colon and spinal cord tissues were decreased in the SCI group (both $\mathrm{P}<0.01$ ). Compared with the SCI group, 5-HT expression levels were elevated in the SNS group (both $\mathrm{P}<0.01)$. However, when compared to the sham group, 5-HT content in the colon and spinal cord tissues was lower in the SNS group $(\mathrm{P}<0.01$ and $\mathrm{P}<0.05$ respectively). These results suggested that SNS could restore 5-HT expression after SCI.

SNS increases 5-HT3AR and 5-HT4R protein levels. IHC was performed to determine the effects of SCI and SNS on 5-HT3AR and 5-HT4R protein levels in the colonic myenteric nerve plexus, colonic mucosa, sacral intermediolateral nucleus and dorsal horn of sacral cord. As presented in Fig. 5A, positive staining for 5-HT3AR/5-HT4R was present in the colonic myenteric plexus (cytoplasmic and nuclear staining). In the colonic myenteric plexus, cells positive for 5-HT3AR and 5-HT4R were continuously and densely distributed in the sham group; positive cells were scattered (a few faintly stained cells) in the SCI group, but densely distributed in the SNS group. In the SCI group, the AOD values of 5-HT3AR and 5-HT4R staining were significantly lower in the colonic myenteric plexus compared with the sham group $(\mathrm{P}<0.01$ and $\mathrm{P}<0.05$, respectively). In the SNS group, the AOD values of 5-HT3AR and 5-HT4R staining were elevated in the colonic myenteric plexus vs. the SCI groups $(\mathrm{P}<0.01, \mathrm{P}<0.05$, respectively; Fig. 5A). Compared with the sham group, the numbers of 5-HT3AR positive cells in the colonic myenteric nerve plexus of the SCI and SNS groups were significantly lower $(\mathrm{P}<0.01)$. Compared with the sham group, the numbers of 5-HT4R positive cells in the colonic myenteric nerve plexus of the SCI group were significantly lower $(\mathrm{P}<0.01)$; however, there was no significant difference in the SNS group. Compared with the SCI group, the number of 5-HT3AR and 5 -HT4R positive cells in the SNS group was significantly higher $(\mathrm{P}<0.01$; Fig. $5 \mathrm{~A})$.

In the colonic mucosa (Fig. 5B), cells positive for 5-HT3AR and 5-HT4R were densely distributed and strongly stained in the sham group, while scattered and faintly stained in the SCI group, and more densely distributed and moderately stained in the SNS group. Compared with the sham group, the AOD values of 5-HT3AR and 5-HT4R staining were significantly decreased in the colonic mucosa of the SCI group $(\mathrm{P}<0.05)$. Compared with the SCI group, the AOD values of 5-HT3AR and 5-HT4R staining in the colonic mucosa were significantly elevated in the SNS group $(\mathrm{P}<0.01$ and $\mathrm{P}<0.05$, respectively; Fig. 5B). Compared with the sham group, the numbers of 5-HT3AR and 5-HT4R positive cells in the colonic mucosa of the SCI group were significantly lower $(\mathrm{P}<0.01)$; however, there was no significant difference in the SNS group. Compared with the SCI group, the number of 5-HT3AR and 
A
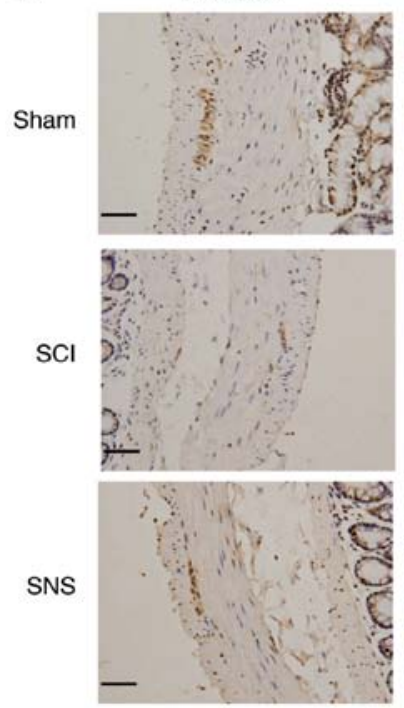

B

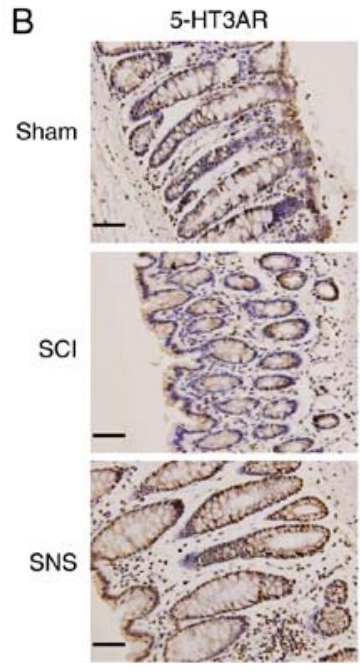

5-HT4R
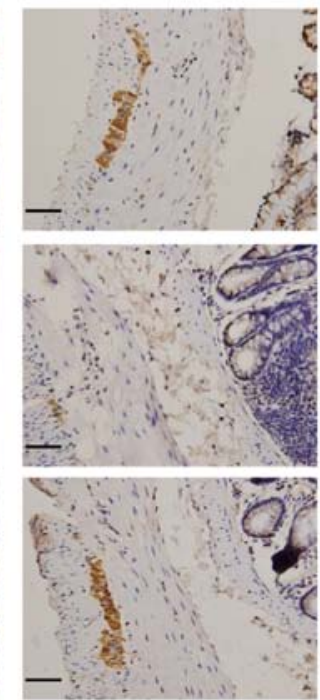

5-HT4R

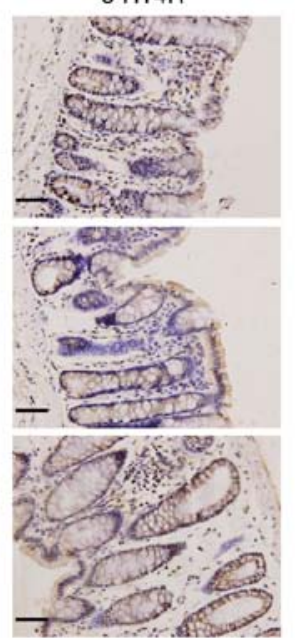

Colonic myenteric nerve plexus Colonic myenteric nerve plexus
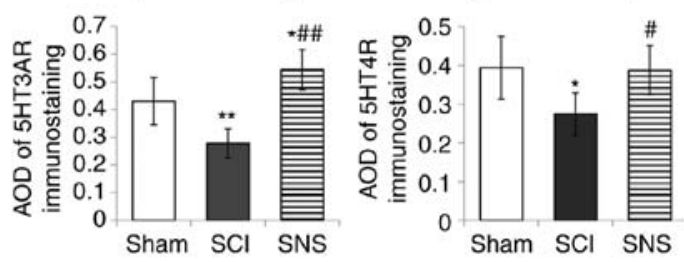

Colonic myenteric nerve plexus Colonic myenteric nerve plexus

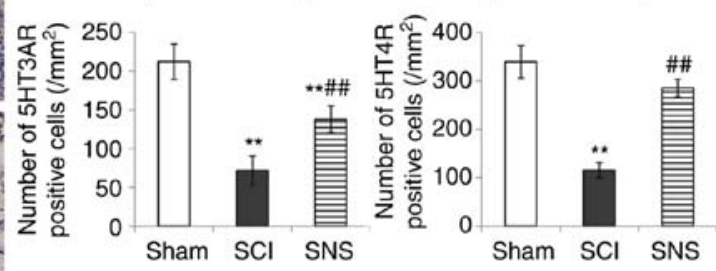

Figure 5. Immunohistochemistry was performed to determine the effects of SCI and SNS on 5-HT3AR and 5-HT4R protein levels. Protein levels of 5-HT3AR and 5-HT4R in the (A) colonic myenteric nerve plexus and (B) colonic mucosa (scale bar, $50 \mu \mathrm{m}$ ). ${ }^{*} \mathrm{P}<0.05 \mathrm{vs}$. sham; ${ }^{* *} \mathrm{P}<0.01 \mathrm{vs}$. sham; ${ }^{\#} \mathrm{P}<0.05 \mathrm{vs}$. SCI; ${ }^{\# \#} \mathrm{P}<0.01$ vs. SCI. SCI, spinal cord injury; SNS, sacral nerve electrical stimulation; 5-HT, serotonin; R, receptor; AOD, average optical density.

5-HT4R positive cells in the SNS group was significantly higher ( $\mathrm{P}<0.01$; Fig. 5B).

As shown in Fig. $5 \mathrm{C}$ and $\mathrm{D}$, in the sacral intermediolateral nucleus and the dorsal horn of the sacral cord, 5-HT3AR and 5-HT4R positive cells were moderately stained in the sham and SCI groups, while they were strongly stained in the SNS group. There were no differences in the AOD values and number of positive cells of 5-HT3AR and 5-HT4R between the sham and SCI groups (all $\mathrm{P}>0.05$ ). The AOD values of 5-HT3AR and 5-HT4R were higher in the SNS group compared with the sham and SCI groups (all $\mathrm{P}<0.05$ ), but there was no difference in the number of positive cells (all $\mathrm{P}>0.05$; Fig. $5 \mathrm{C}$ and $\mathrm{D}$ ). Taken together, these results suggested that SCI decreased 5-HT3AR and 5-HT4R protein expression in the colon of rats, while SNS appeared to promote 5-HTR expression to above-sham levels.

Validation of the effects of SNS on 5-HT3AR/5-HT4R gene and protein expression in the colon and sacral spinal cord. In order to validate the IHC results, RT-qPCR and western blotting were performed. Compared with the sham group, the relative expression levels of 5-HT3AR and 5-HT4R mRNA and protein were both downregulated in colon tissue (all $\mathrm{P}<0.05$; Figs. $6 \mathrm{~A}$ and $\mathrm{B} ; 7 \mathrm{~A}$ and $\mathrm{B}$ ), but there was no significant difference in the sacral cord (both $\mathrm{P}>0.05$ ) in the SCI group (Figs. 6C and D; 7C and D). In the SNS group, the relative 5-HT3AR mRNA (Fig. 6A) and protein levels (Fig. 7A) were elevated compared with the SCI group (all $\mathrm{P}<0.05$ ) in the colon tissues. The relative 5-HT3AR and 5-HT4R mRNA (Fig. 6C and D) and protein levels (Fig. 7C and D) were both elevated in sacral cord tissues compared with the SCI group (all $\mathrm{P}<0.05$ ). Compared with the SCI group, the relative expression levels of 5-HT3AR and 5-HT4R mRNA (Fig. 6) and protein (Fig. 7) in the colon and sacral cord tissues were elevated in the SNS group (all $\mathrm{P}<0.05$ ). Taken together, these results validated the IHC results.

\section{Discussion}

Changes in 5-HT, 5-HT3AR and 5-HT4R expression in the colon and spinal cord of rats with SCI remain to be clarified. The 

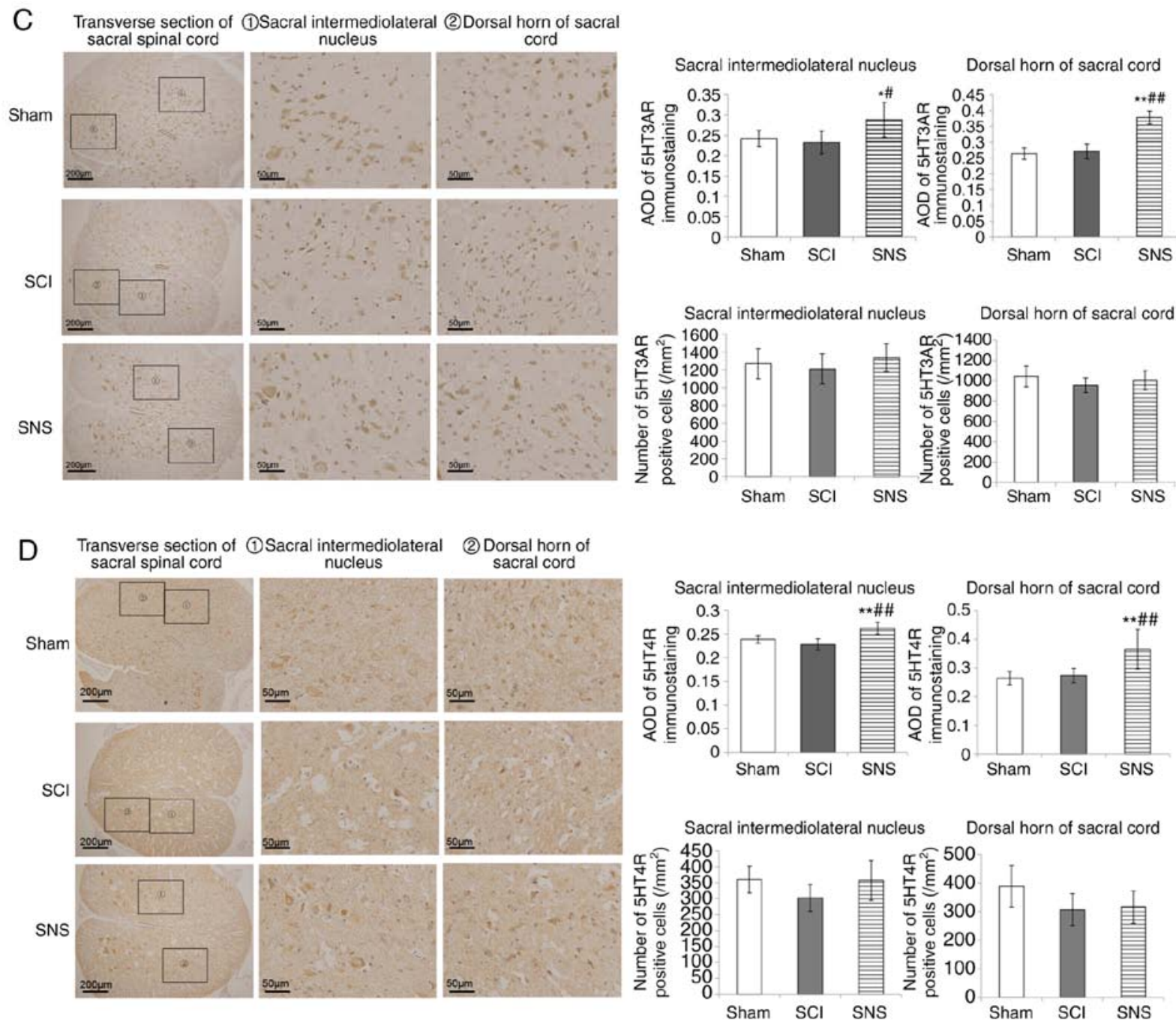

Figure 5. Continued. Immunohistochemistry was performed to determine the effects of SCI and SNS on 5-HT3AR and 5-HT4R protein levels. Effects of SCI and SNS on (C) 5-HT3AR and (D) 5-HT4R protein levels in the sacral intermediolateral nucleus and dorsal horn of the sacral cord (magnifications, x100 and x400; $\mathrm{n}=5$ ). ${ }^{*} \mathrm{P}<0.05$ vs. sham; ${ }^{* *} \mathrm{P}<0.01$ vs. sham; ${ }^{~} \mathrm{P}<0.05$ vs. SCI; ${ }^{* \#} \mathrm{P}<0.01$ vs. SCI. SCI, spinal cord injury; SNS, sacral nerve electrical stimulation; 5-HT, serotonin; $\mathrm{R}$, receptor; AOD, average optical density.

neuromodulatory mechanism underlying SNS therapy for SCI also remains to be determined. Therefore, the aim of the present study was to establish a rat model of acute severe SCI (thoracic segments) to assess the influence of SNS on 5-HT, 5-HT3AR and 5-HT4R in the colon and sacral cord. In SCI rats, SNS significantly increased the amount of defecation, shortened the time to first black feces, and improved the fecal texture and colon histology. SNS elevated 5-HT contents in the colon and spinal cord tissues, and enhanced 5-HT3AR and 5-HT4R protein expression and distribution in the colonic myenteric plexus and mucosa, sacral intermediolateral nucleus and dorsal horn. It also upregulated the relative expression levels of 5-HT3AR/5-HT4R mRNA and protein in the colon and spinal cord. Taken together, these results suggested that SNS can elevate 5-HT3AR/5-HT4R expression in the sacral defecation center and colon, and elevate colonic 5-HT contents, thus improving defecation and accelerating recovery of the colonic transmission function in acute SCI rats.

5 -HT is mainly secreted by enterochromaffin cells; $>90 \%$ of 5-HT is present in the GI tract, while the remaining portion is found in the CNS (7-10). 5-HT secreted in the gut upon sensation of pressure and chemical stimulation exerts two types of effects; direct effect on the smooth muscle and augmenting enteric motility, and activating the intrinsic primary afferent neurons and modulating gut sensation, motor function and secretion $(7-10,13,15-17)$.

In the present study, SCI modeling led to a significant decrease of 5-HT contents in the colon and sacral cord of rats. It was hypothesized that histopathological changes in the gut wall caused changes in the structure and function of enterochromaffin cells that led to decreased secretion of 5-HT, and thus decreased 5-HT contents in other locations such as the sacral cord. Meanwhile, the downregulation of 5-HT3AR/5-HT4R was associated with the impairment of the gut wall. The decrease in 5-HT contents and 5-HT3AR/5-HT4R expression in the colon not only affected colonic excitability and lowered motility, but also disabled feedback colonic sensation signaling to the nervous center via the ascending afferent fibers of vagus and spinal nerves. Thereby impeding, to a certain degree, the defecation reflex, and increasing constipation. This mechanism of the involvement of 5-HT and 5-HT3AR/5-HT4R in SCI has also been proposed in other studies (48) and is supported by 
A

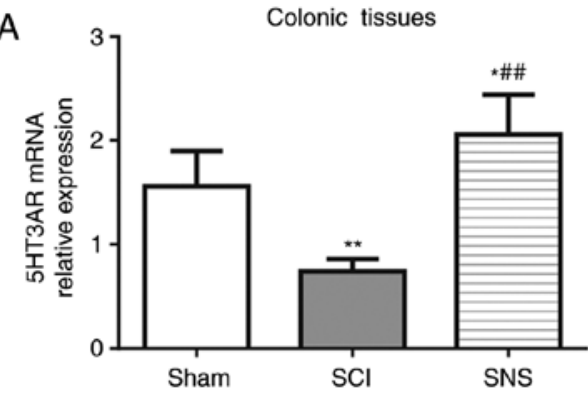

C

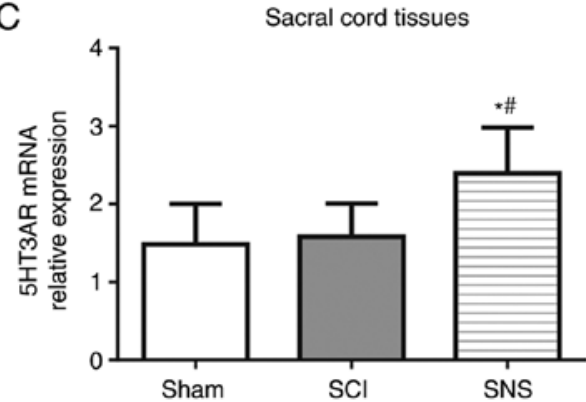

B

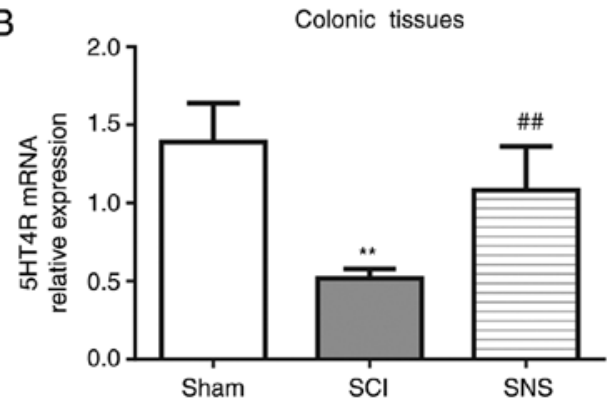

D

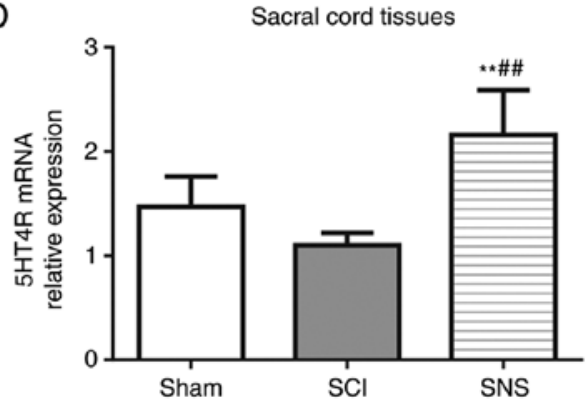

Figure 6. Effect of SNS on 5-HT3AR/5-HT4R gene expression in the colon and sacral spinal cord. Quantitative PCR assays show the mRNA expression of (A) 5-HT3AR and (B) 5-HT4R in the colon and (C) 5-HT3AR and (D) 5-HT4R in the sacral cord (n=5). ${ }^{*} \mathrm{P}<0.05$ vs. sham, ${ }^{* *} \mathrm{P}<0.01 \mathrm{vs}$. sham, ${ }^{*} \mathrm{P}<0.05$ vs. SCI, ${ }^{\# \#} \mathrm{P}<0.01$ vs. SCI. SCI, spinal cord injury; SNS, sacral nerve electrical stimulation; 5-HT, serotonin; R, receptor.
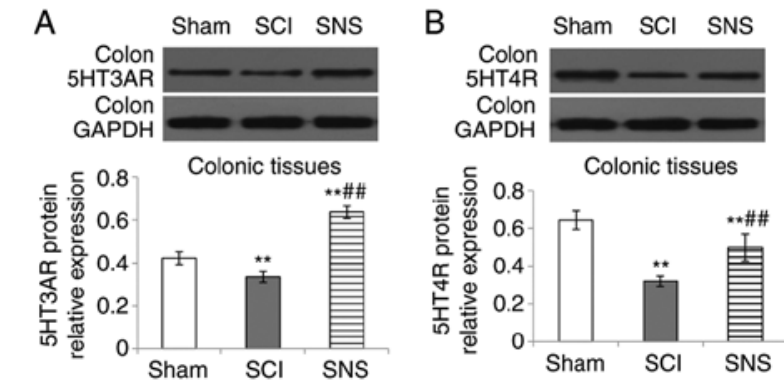

C
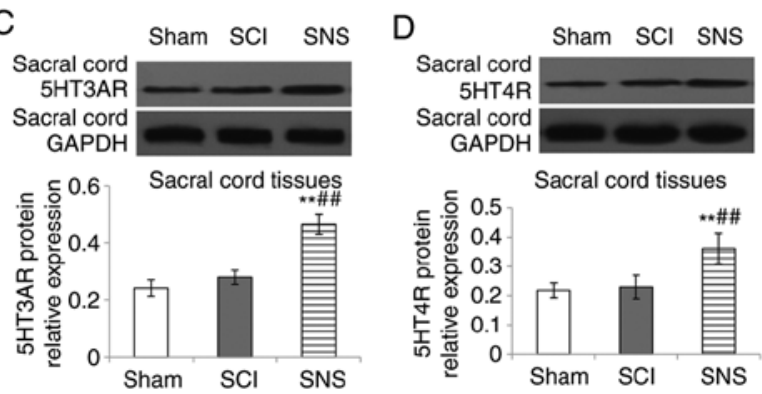

Figure 7. Effect of SNS on 5-HT3AR/5-HT4R protein expression in the colon and sacral spinal cord. Western blot analysis shows the protein expression of (A) 5-HT3AR and (B) 5-HT4R in the colon and (C) 5-HT3AR and (D) 5 -HT4R in the sacral cord $(\mathrm{n}=4) .{ }^{* *} \mathrm{P}<0.01$ vs. sham, ${ }^{\# \#} \mathrm{P}<0.01 \mathrm{vs}$. SCI. SCI, spinal cord injury; SNS, sacral nerve electrical stimulation; 5-HT, serotonin; R, receptor.

the restoration of some colon function by intrathecal infusion of 5-HT agonists (49). In addition, impaired 5-HT axis is likely to affect enteric mucosal secretion and the release of other neurotransmitters that further interfere with the colonic transmission function. Moreover, according to Zhu et al (50), SCI rats with defecation dysfunction had decreased ICCs, degenerated colon function that could be associated with decreased 5-HT contents, and downregulated 5-HT3AR and 5-HT4R expression. Nevertheless, the other neurotransmitters and factors secreted by the colonic mucosa that could impact intestinal function remain to be determined in detail.

SNS acts on the visceral sensory fibers of the sacral nerve and sends excitatory impulses to the sacral cord, thereby activating interneurons in the spinal cord, augmenting afferent impulses of visceral sensation, and exciting the lower center (41). Together, these effects lead to efferent impulses via the visceral motor fibers and increase the contraction of the lower part of the colon and rectum through the pelvic nerve, thereby triggering defecation (43). There are a lack of studies concerning the neurotransmitters and receptors involved in the central and peripheral effects of SNS. Nevertheless, the effects of SNS on improving colonic motility and shortening colon transit time, thereby ameliorating constipation, are well known $(36-39,41)$.

At the molecular level, after SNS, the mRNA and protein levels of 5-HT3AR and 5-HT4R were upregulated in the spinal cord at the S2-4 segments, where the sacral lower defecation center is located (51). Since the expression of 5-HT3AR and 5-HT4R in the spinal cord is positively associated with visceral sensation (52), it is reasonable to assume that this effect of SNS is at least one of the beneficial actions it has on the colon. IHC staining showed that SNS increased the expression of 5-HT3AR and 5-HT4R proteins in the dorsal horn of spinal cord at the S2-4 segments, implying that SNS generates excitatory visceral sensation and conduction to the lower center, as supported by previous studies $(40,41)$. In addition, 5-HT3AR and 5-HT4R proteins were upregulated in the intermediolateral nucleus at the S2-4 segments, associated with the visceral motor and in colonic myenteric plexus.

Based on previous studies and the known effects of 5-HT3AR and 5-HT4R on intestinal function (13,15-17), it can 
be speculated that the effects of SNS are due to the upregulation of 5-HT3AR and 5-HT4R. Nevertheless, the present study was not designed to determine how SNS improved colonic histology and function, and how it can upregulate 5-HT3AR and 5-HT4R expression.

However, the present study does have limitations. There was no control group of rats without SCI that were treated with SNS. In addition, the present study was performed in the acute phase of SCI and additional studies are necessary to confirm the results in chronic SCI. Inflammation should also be examined in future studies. As the low-level center for colonic motility is in S2-S4, only the spinal samples of S2-S4 were obtained in this study. Samples from the other levels were not obtained. Finally, only 5-HT3AR and 5-HT4R were studied, it is likely that SNS affects the neurons as a whole, rather than only specifically 5-HT3AR and 5-HT4R. In addition, 5-HT3AR and 5-HT4R were only examined at S2-4 and it is unknown whether they are changed at other levels.

Additional studies are necessary to examine these issues. In particular, the studies of other neurotransmitters and factors secreted by the colonic mucosa could shed additional light on the matter. Period circadian protein 2 (Per2) is known to be involved in the colonic circadian rhythm and electroacupuncture has been shown to affect Per2 expression in rats with SCI (53). Per2 should be studied in relation to 5-HT in SCI models. Nitric oxide and oxidative stress are also involved in the effect of electroacupuncture on intestinal function in SCI (54). The aim of the present study was to investigate whether SNS could up-regulate 5-HT and 5-HT3AR/5-HT4R to improve the recovery of fecal discharge functions in rat models of SCI. Future studies should examine the mechanisms responsible for SNS upregulating 5-HT and 5-HT3AR/5-HT4R. Taken together, these studies and the present one indicate that intestinal function in SCI is a complex process. Additional and comprehensive studies are necessary to unravel the exact mechanisms.

To conclude, SNS increases 5-HT3AR/5-HT4R expression in the sacral defecation center, increases 5-HT content and 5-HT3AR/5-HT4R expression in the colon, improves the defecation reflex, and promotes the recovery of the colonic transmission function in rats with SCI.

\section{Acknowledgements}

Not applicable.

\section{Funding}

The study was supported by grants from China Postdoctoral Science Foundation (grant no. 2016M602847) and the Natural Science Foundation of Shaanxi Province (grant no. 20168291).

\section{Availability of data and materials}

The datasets used and/or analyzed during the current study are available from the corresponding author on reasonable request.

\section{Authors' contributions}

YZ and JC carried out the studies, participated in collecting data and drafted the manuscript. JY participated in the analysis and interpretation of data. YY, JG, and WZ acquired the data. BX performed the animal experiments and acquired the behavioral data. HL and DH participated in the analysis and interpretation of the data, and drafted the manuscript. All authors read and approved the final manuscript.

\section{Ethics approval and consent to participate}

We certify that all applicable institutional and governmental regulations concerning the ethical use of animals were followed during the course of this research. The experiments were approved by the Animal Care and Use Committee of Xi'an Jiaotong University Health Science Center.

\section{Patient consent for publication}

Not applicable.

\section{Competing interests}

The authors declare that they have no competing interests.

\section{References}

1. DeVivo MJ and Vogel LC: Epidemiology of spinal cord injury in children and adolescents. J Spinal Cord Med 27 (Suppl 1): S4-S10, 2004.

2. Lynch AC, Antony A, Dobbs BR and Frizelle FA: Bowel dysfunction following spinal cord injury. Spinal Cord 39: 193-203, 2001.

3. Liu CW, Huang CC, Yang YH, Chen SC, Weng MC and Huang MH: Relationship between neurogenic bowel dysfunction and health-related quality of life in persons with spinal cord injury. J Rehabil Med 41: 35-40, 2009.

4. Piatt JA, Nagata S, Zahl M, Li J and Rosenbluth JP: Problematic secondary health conditions among adults with spinal cord injury and its impact on social participation and daily life. J Spinal Cord Med 39: 693-698, 2016.

5. Brading AF and Ramalingam T: Mechanisms controlling normal defecation and the potential effects of spinal cord injury. Prog Brain Res 152: 345-358, 2006.

6. Krassioukov A, Eng JJ, Claxton G, Sakakibara BM and Shum S: Neurogenic bowel management after spinal cord injury: A systematic review of the evidence. Spinal Cord 48: 718-733, 2010.

7. Grundy D: 5-HT system in the gut: Roles in the regulation of visceral sensitivity and motor functions. Eur Rev Med Pharmacol Sci 12 (Suppl 1): S63-S67, 2008.

8. Linan-Rico A, Ochoa-Cortes F, Beyder A, Soghomonyan S, Zuleta-Alarcon A, Coppola V and Christofi FL: Mechanosensory signaling in enterochromaffin cells and 5-HT release: Potential implications for gut inflammation. Front Neurosci 10: 564, 2016.

9. Wouters MM, Gibbons SJ, Roeder JL, Distad M, Ou Y, Strege PR, Szurszewski JH and Farrugia G: Exogenous serotonin regulates proliferation of interstitial cells of Cajal in mouse jejunum through 5-HT2B receptors. Gastroenterology 133: 897-906, 2007.

10. Camilleri M: Serotonergic modulation of visceral sensation: Lower gut. Gut 51 (Suppl 1): i81-i86, 2002.

11. Sveshnikov DS, Torshin VI, Smirnov VM, Kuchuk AV and Myasnikov IL: The significance of different 5-HT-receptors in regulation of gastrointestinal motility. Patol Fiziol Eksp Ter 45-51: 2014 (In Russian).

12. Yu Y, Chen JH, Li H, Yang Z, Du X, Hong L, Liao H, Jiang L, Shi J, Zhao L, et al: Involvement of 5-HT3 and 5-HT4 receptors in colonic motor patterns in rats. Neurogastroenterol Motil 27: 914-928, 2015.

13. Machu TK: Therapeutics of 5-HT3 receptor antagonists: Current uses and future directions. Pharmacol Ther 130: 338-347, 2011.

14. Faerber L, Drechsler S, Ladenburger S, Gschaidmeier H and Fischer W: The neuronal 5-HT3 receptor network after 20 years of research-evolving concepts in management of pain and inflammation. Eur J Pharmacol 560: 1-8, 2007. 
15. Liu HN, Ohya S, Nishizawa Y, Sawamura K, Iino S, Syed MM, Goto K, Imaizumi Y and Nakayama S: Serotonin augments gut pacemaker activity via 5-HT3 receptors. PLoS One 6: e24928, 2011.

16. Ozcan CU, Yilmaz O, Gurer DE, Ayhan S, Taneli C and Genc A: Evaluation of the relation between interstitial cells of cajal (CD117) and serotonin receptor (5HT-3A) with postfundoplication dysphagia. Int J Surg 13: 137-141, 2015.

17. Talley NJ: Review article: 5-hydroxytryptamine agonists and antagonists in the modulation of gastrointestinal motility and sensation: Clinical implications. Aliment Pharmacol Ther 6: 273-289, 1992

18. Gershon MD: Review article: Roles played by 5-hydroxytryptamine in the physiology of the bowel. Aliment Pharmacol Ther 13 (Suppl 2): S15-S30, 1999.

19. Bhattarai Y, Schmidt BA, Linden DR, Larson ED, Grover M, Beyder A, Farrugia G and Kashyap PC: Human-derived gut microbiota modulates colonic secretion in mice by regulating 5-HT3 receptor expression via acetate production. Am J Physiol Gastrointest Liver Physiol 313: G80-G87, 2017.

20. Yaakob N, Malone DT, Exintaris B and Irving HR: Heterogeneity amongst 5-HT(3) receptor subunits: Is this significant? Curr Mol Med 11: 57-68, 2011.

21. Yan C, Xin-Guang L, Hua-Hong W, Jun-Xia L and Yi-Xuan L: Effect of the 5-HT4 receptor and serotonin transporter on visceral hypersensitivity in rats. Braz J Med Biol Res 45: 948-954, 2012

22. Mader R, Kocher T, Haier J, Wieczorek G, Pfannkuche HJ and Ito $\mathrm{M}$ : Investigation of serotonin type 4 receptor expression in human and non-human primate gastrointestinal samples. Eur J Gastroenterol Hepatol 18: 945-950, 2006.

23. Gilet M, Eutamene H, Han H, Kim HW and Bueno L: Influence of a new 5-HT4 receptor partial agonist, YKP10811, on visceral hypersensitivity in rats triggered by stress and inflammation. Neurogastroenterol Motil 26: 1761-1770, 2014.

24. Liu M, Geddis MS, Wen Y, Setlik W and Gershon MD Expression and function of 5-HT4 receptors in the mouse enteric nervous system. Am J Physiol Gastrointest Liver Physiol 289: G1148-G1163, 2005

25. Emerit MB, Baranowski C, Diaz J, Martinez A, Areias J, Alterio J, Masson J, Boué-Grabot E and Darmon M: A new mechanism of receptor targeting by interaction between two classes of ligand-gated ion channels. J Neurosci 36: 1456-1470, 2016.

26. Glatzle J, Sternini C, Robin C, Zittel TT, Wong H, Reeve JR Jr and Raybould HE: Expression of 5-HT3 receptors in the rat gastrointestinal tract. Gastroenterology 123: 217-226, 2002.

27. Liu MT, Rayport S, Jiang Y, Murphy DL and Gershon MD: Expression and function of 5-HT3 receptors in the enteric neurons of mice lacking the serotonin transporter. Am J Physio Gastrointest Liver Physiol 283: G1398-G1411, 2002.

28. Freeman SL, Glatzle J, Robin CS, Valdellon M, Sternini C Sharp JW and Raybould HE: Ligand-induced 5-HT3 receptor internalization in enteric neurons in rat ileum. Gastroenterology 131: 97-107, 2006

29. Morita H, Mochiki E, Takahashi N, Kawamura K, Watanabe A, Sutou T, Ogawa A, Yanai M, Ogata K, Fujii T, et al: Effects of 5-HT2B, 5-HT3 and 5-HT4 receptor antagonists on gastrointestinal motor activity in dogs. World J Gastroenterol 19: 6604-6612, 2013

30. Chen JH, Zhang Q, Yu Y, Li K, Liao H, Jiang L, Hong L, Du X, $\mathrm{Hu} \mathrm{X}$, Chen S, et al: Neurogenic and myogenic properties of pan-colonic motor patterns and their spatiotemporal organization in rats. PLoS One 8: e60474, 2013

31. Jeong EJ, Chung SY, Hong HN, Oh SW and Sim JY: The novel, potent and highly selective 5-HT4 receptor agonist YH12852 significantly improves both upper and lower gastrointestinal motility. Br J Pharmacol 175: 485-500, 2018.

32. Nardone R, Höller Y, Thomschewski A, Höller P, Lochner P, Golaszewski S, Brigo F and Trinka E: Serotonergic transmission after spinal cord injury. J Neural Transm (Vienna) 122: 279-295, 2015.

33. Koyama Y, Kondo M and Shimada S: Building a 5-HT3A receptor expression map in the mouse brain. Sci Rep 7: 42884, 2017.

34. Zhou J, Li H, Liu XY, Wang YY, Li YQ and Wu SX: Expression of 5-HT2, 4, 5 receptor subtype mRNAs in rat spinal dorsal and ventral horns of different segments. J Fourth Mil Med Univ 25 1345-1348, 2004.
35. Sun J, Wu X, Meng Y, Cheng J, Ning H, Peng Y, Pei L and Zhang W: Electro-acupuncture decreases 5-HT, CGRP and increases NPY in the brain-gut axis in two rat models of Diarrhea-predominant irritable bowel syndrome (D-IBS). BMC Complement Altern Med 15: 340, 2015.

36. Iqbal F, Thomas GP, Tan E, Askari A, Dastur JK, Nicholls J and Vaizey CJ: Transcutaneous sacral electrical stimulation for chronic functional constipation. Dis Colon Rectum 59: 132-139, 2016.

37. Fassov J, Brock C, Lundby L, Drewes AM, Gregersen H, Buntzen S, Laurberg S and Krogh K: Sacral nerve stimulation changes rectal sensitivity and biomechanical properties in patients with irritable bowel syndrome. Neurogastroenterol Motil 26: 1597-1604, 2014.

38. Dinning PG, Hunt L, Patton V, Zhang T, Szczesniak M, Gebski V, Jones M, Stewart P, Lubowski DZ and Cook IJ: Treatment efficacy of sacral nerve stimulation in slow transit constipation: A two-phase, double-blind randomized controlled crossover study. Am J Gastroenterol 110: 733-740, 2015.

39. Worsøe J, Fynne L, Laurberg S, Krogh K and Rijkhoff NJ: Acute effect of electrical stimulation of the dorsal genital nerve on rectal capacity in patients with spinal cord injury. Spinal Cord 50: 462-466, 2012.

40. Worsøe J, Rasmussen M, Christensen P and Krogh K: Neurostimulation for neurogenic bowel dysfunction. Gastroenterol Res Pract 2013: 563294, 2013.

41. Elkelini MS, Pravdivyi I and Hassouna MM: Mechanism of action of sacral nerve stimulation using a transdermal amplitude-modulated signal in a spinal cord injury rodent model. Can Urol Assoc J 6: 227-230, 2012

42. Gourcerol G, Vitton V, Leroi AM, Michot F, Abysique A and Bouvier M: How sacral nerve stimulation works in patients with faecal incontinence. Colorectal Dis 13: e203-e211, 2011.

43. Abdel-Halim M: Studies of the Mechanisms of Sacral Nerve Stimulation for Faecal Incontinence: Investigations of Anorectal and Pelvic Floor Physiology and Function. University College London, Division of Surgery and Interventional Science, 2012.

44. Thomas AJ, Nockels RP, Pan HQ, Shaffrey CI and Chopp M: Progesterone is neuroprotective after acute experimental spinal cord trauma in rats. Spine (Phila Pa 1976) 24: 2134-2138, 1999.

45. Basso DM, Beattie MS and Bresnahan JC: A sensitive and reliable locomotor rating scale for open field testing in rats. J Neurotrauma 12: 1-21, 1995.

46. Barbalias GA, Klauber GT and Blaivas JG: Critical evaluation of the Crede maneuver: A urodynamic study of 207 patients. J Urol 130: 720-723, 1983.

47. Livak KJ and Schmittgen TD: Analysis of relative gene expression data using real-time quantitative PCR and the 2(-Delta Delta C(T)) method. Methods 25: 402-408, 2001

48. Awad RA: Neurogenic bowel dysfunction in patients with spinal cord injury, myelomeningocele, multiple sclerosis and Parkinson's disease. World J Gastroenterol 17: 5035-5048, 2011.

49. Guertin PA: New pharmacological approaches against chronic bowel and bladder problems in paralytics. World J Crit Care Med 5: 1-6, 2016

50. Zhu Y, Yang Y, Guo J, Zhang W, Zhu Z, Xie B, Yu J and Cheng J: Abdominal manual therapy repairs interstitial cells of cajal and increases colonic c-Kit expression when treating bowel dysfunction after spinal cord injury. Biomed Res Int 2017: 1492327, 2017.

51. Shafik A: Recto-colic reflex: Role in the defecation mechanism. Int Surg 81: 292-294, 1996.

52. Zhao JM, Li L, Chen L, Shi Y, Li YW, Shang HX, Wu LY, Weng ZJ, Bao CH and Wu HG: Comparison of the analgesic effects between electro-acupuncture and moxibustion with visceral hypersensitivity rats in irritable bowel syndrome. World J Gastroenterol 23: 2928-2939, 2017.

53. Cheng J, Wang X, Guo J, Yang Y, Zhang W, Xie B, Zhu Z, Lu Y and Zhu Y: Effects of electroacupuncture on the daily rhythmicity of intestinal movement and circadian rhythmicity of colonic Per2 expression in rats with spinal cord injury. Biomed Res Int 2016: 9860281, 2016

54. Guo J, Zhu Y, Yang Y, Wang X, Chen B, Zhang W, Xie B, Zhu Z, Yue Y and Cheng J: Electroacupuncture at Zusanli (ST36) ameliorates colonic neuronal nitric oxide synthase upregulation in rats with neurogenic bowel dysfunction following spinal cord injury. Spinal Cord 54: 1139-1144, 2016.

This work is licensed under a Creative Commons Attribution-NonCommercial-NoDerivatives 4.0 International (CC BY-NC-ND 4.0) License. 